\title{
Characterizing leaf area index (LAI) and vertical foliage profile (VFP) over the United States
}

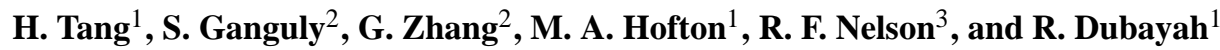 \\ ${ }^{1}$ Department of Geographical Sciences, University of Maryland, College Park, Maryland, USA \\ ${ }^{2}$ Bay Area Environmental Research Institute (BAERI) / NASA Ames Research Center, Moffett Field, California, USA \\ ${ }^{3}$ Biospheric Sciences Branch, Code 618, NASA Goddard Space Flight Center, Greenbelt, Maryland, USA
}

Correspondence to: H. Tang (htang@umd.edu)

Received: 4 July 2015 - Published in Biogeosciences Discuss.: 24 August 2015

Revised: 26 November 2015 - Accepted: 17 December 2015 - Published: 15 January 2016

\begin{abstract}
Leaf area index (LAI) and vertical foliage profile (VFP) are among the important canopy structural variables. Recent advances in lidar remote sensing technology have demonstrated the capability of accurately mapping LAI and VFP over large areas. The primary objective of this study was to derive and validate a LAI and VFP product over the contiguous United States (CONUS) using spaceborne waveform lidar data. This product was derived at the footprint level from the Geoscience Laser Altimeter System (GLAS) using a biophysical model. We validated GLAS-derived LAI and VFP across major forest biomes using airborne waveform lidar. The comparison results showed that GLAS retrievals of total LAI were generally accurate with little bias $\left(r^{2}=0.67\right.$, bias $=-0.13$, RMSE $=0.75)$. The derivations of GLAS retrievals of VFP within layers were not as accurate overall $\left(r^{2}=0.36\right.$, bias $\left.=-0.04, \mathrm{RMSE}=0.26\right)$, and these varied as a function of height, increasing from understory to overstory -0 to $5 \mathrm{~m}$ layer: $r^{2}=0.04$, bias $=0.09$, RMSE $=0.31 ; 10$ to 15 m layer: $r^{2}=0.53$, bias $=-0.08$, RMSE $=0.22$; and 15 to 20 m layer: $r^{2}=0.66$, bias $=-0.05$, RMSE $=0.20$. Significant relationships were also found between GLAS LAI products and different environmental factors, in particular elevation and annual precipitation. In summary, our results provide a unique insight into vertical canopy structure distribution across North American ecosystems. This data set is a first step towards a baseline of canopy structure needed for evaluating climate and land use induced forest changes at the continental scale in the future, and should help deepen our understanding of the role of vertical canopy structure in terrestrial ecosystem processes across varying scales.
\end{abstract}

\section{Introduction}

Accurate measurements of three-dimensional canopy structure and function play a key role in global carbon dynamics, climate feedbacks as well as biodiversity studies (Heimann and Reichstein, 2008; Loreau et al., 2001; Cramer et al., 2001; Schimel et al., 2001). Spatial variations of ecosystem structure largely inform the geographical patterns of ecological processes, including species richness (Cramer et al., 2001; Goetz et al., 2007; Turner et al., 2003). These structural variables, such as canopy height, leaf area index (LAI) and vertical foliage profile (VFP), have been identified as essential climate variables (ECV), essential biodiversity variables (EBV), or both (Pereira et al., 2013; Aber, 1979; Gower and Norman, 1991; Baret et al., 2013). Yet measurements of these canopy structural data are often limited at field sites, and their spatial distributions over broader geographical areas still remain poorly characterized due to heterogeneity of natural vegetation and inexact measuring techniques (Clark and Kellner, 2012; Asner et al., 2013). Improved spatial characterization of LAI and VFP at large scales may fill this observational gap and help clarify the role of spatial and vertical variability in canopy structure for carbon cycling, biodiversity and habitat quality (Houghton, 2007; Sauer et al., 2008).

Several global-scale LAI products have been created from passive remote sensing data for many years (Myneni et al., 2002; Ganguly et al., 2012; Deng et al., 2006; Baret et al., 2007). Most of these products are derived by exploring the correlation between canopy foliage density and the total reflected intensity of electromagnetic radiation at multiple wavelengths. Applications of these LAI products have significantly improved the representation of the dynamics of 
terrestrial ecosystems and their interactions with the atmosphere (Mu et al., 2007; Zhao et al., 2005; Randerson et al., 2009). However, the overall accuracy of these products does not meet the requirements as specified by the Global Terrestrial Observing System (GTOS: http://www.fao.org/gtos/org. $\mathrm{html}$ ), and a key problem is the saturation of spectral signal over dense forests with high canopy cover (Abuelgasim et al., 2006; Shabanov et al., 2005; Yang et al., 2006). Saturation occurs because the solar flux decreases exponentially as it passes through a dense canopy, and the majority of the returned signal comes from the upper canopy in the form of direct reflectance and multiple scattering (Gower and Norman, 1991; Nilson, 1971). This limits the observational capabilities of passive optical sensors, such as Landsat and MODIS, to estimate LAI over dense forests. Furthermore, deriving the foliage profile as a function of height is beyond the capability of passive optical remote sensing, unless multiple look angles are used (Chopping et al., 2009). We argue that spaceborne lidar (light detection and ranging) technology provides a means of overcoming this limitation and of measuring vertical structure even over dense forests.

Lidar has proven effective at measuring three-dimensional canopy structural information (Lefsky et al., 2002). Lidar measures the distance between a target and the sensor by the round-trip traveling time of an emitted laser pulse. It allows direct three-dimensional measurements of canopy structural components, including foliage, branch and trunk, which then can be used to estimate biophysical variables, such as canopy height and biomass (Drake et al., 2002; Saatchi et al., 2011; Los et al., 2012; Lefsky, 2010; Simard et al., 2011; Asner et al., 2012; Baccini et al., 2012; Strahler et al., 2008), as well as LAI and VFP (Morsdorf et al., 2006; Tang et al., 2012; Zhao et al., 2013).

Garcia et al. (2012) and Luo et al. (2013) demonstrated the possibility of deriving LAI and VFP data across different landscapes from the Geoscience Laser Altimeter System (GLAS) onboard the Ice, Cloud and land Elevation Satellite (ICESat). Tang et al. (2014a) derived LAI and VFP data from GLAS data, but using a physically based model rather than an empirical methodology. The use of a physical model greatly simplified application over large areas because site-specific, statistical calibrations were not required. Further improvement of the model led to a GLAS LAI and VFP product over the entire state of California, USA (Tang et al., 2014b). However, there is still a need to further examine the relationship between vertical foliage distribution and lidar waveforms over even broader areas. Assessment of their relationship across different forest types and environmental gradients will not only strengthen our confidence in acquiring a potential global LAI and VFP measurement, but will also provide guidance on the design and science definition of future lidar missions such as the Global Ecosystem Dynamics Investigation (GEDI) (Dubayah et al., 2014).

The objective of this study is to characterize the continental-scale variability of canopy structure across the
United States using lidar observations from space. First, we implement our existing algorithm at the GLAS footprint level and compare the derived data with LAI and VFP products from airborne lidar in different forest types. Next we map the aggregated LAI and VFP product according to different ecoregions and land cover types over the contiguous United States (CONUS). Finally we analyze the distribution of GLAS LAI across different environmental factors, including elevation and precipitation.

\section{Methods}

\subsection{GLAS data}

GLAS is a spaceborne, sampling waveform lidar sensor with the working wavelength in the near-infrared band $(1064 \mathrm{~nm})$. It emits laser pulses at a frequency of $40 \mathrm{~Hz}$ and records the energy reflected from both the ground surface and canopy in an approximately $65 \mathrm{~m}$ diameter footprint (Abshire et al., 2005). GLAS samples the Earth's surface in transects with individual footprints separated by $\sim 175 \mathrm{~m}$ along track, and with between-track spacing that varies as a function of latitude (e.g., $30 \mathrm{~km}$ spacing between tracks at the Equator and $5 \mathrm{~km}$ spacing at $80^{\circ}$ latitude, Brenner et al., 2012). As a result of this sampling pattern, GLAS does not provide a wallto-wall observation of forests. Its spatial allocation of laser footprints is best defined as a pseudo-systematic sampling or cluster sampling strategy (Stahl et al., 2011; Healey et al., 2012). To obtain a spatially continuous estimate of LAI at continental scale, footprint level GLAS data would need to be extrapolated using other remote sensing data (Dubayah et al., 2008; Lefsky, 2010), or can be mapped into appropriate geographic strata such as land cover types or ecoregions.

\subsection{Retrieval of GLAS LAI and VFP}

We collected a total of 1100498 cloud-free GLAS data from campaigns GLA01 and GLA14 data over the contiguous United States from 2003 to 2007. GLA01 included the complete recorded waveform at a vertical resolution of $15 \mathrm{~cm}$ for land surface products, and GLA14 products were comprised of geographical information and various parameters calculated from the waveform (Harding and Carabajal, 2005). Low-energy shots (peak energy $<0.5 \mathrm{~V}$ ) were excluded from the data process for retrieval quality control because those waveforms were susceptible to noise contamination. Shots during the leaf-off season (November to March) were also filtered out over deciduous forests and mixed forests. LAI and its profiles $(0.15 \mathrm{~m}$ at vertical resolution) were initially calculated for GLAS footprints based on the Geometric Optical and Radiative Transfer (GORT) model (Ni-Meister et al., 2001) and further corrected for slope effects using an iterative method (Tang et al., 2014a). Canopy VFPs were calculated from integration of footprint level LAI profiles at height intervals of 0 to 5,5 to 10,10 to 15 , and 15 to $20 \mathrm{~m}$. More 
details of the GLAS data processing can be found in the Supplement.

\subsection{Comparison data sets}

We validated LAI and VFP data sets using an airborne lidar system, LVIS (Laser Vegetation Imaging Sensor). LVIS is a medium-resolution $(\sim 25 \mathrm{~m}$ diameter $)$ waveform scanning lidar system designed by NASA Goddard Space Flight Center (GSFC) (Blair et al., 1999). It can image the terrestrial surface across a $2 \mathrm{~km}$ wide swath and has been deployed to map many different forest structural parameters at regional scales across diverse biomes (Tang et al., 2012; Drake et al., 2002; Swatantran et al., 2012). We calculated both total LAI and VFP at $5 \mathrm{~m}$ height intervals from existing LVIS data using our physically based model, which has been validated using different types of field measurements (destructive sampling, LAI-2000 and hemispherical photos) (Tang et al., 2012, 2014a; Zhao et al., 2013). LVIS data used in this study included major forest types from the eastern, central and western US, including Maine forests just north of Orono, Maine (2003), Sierra National Forest in California (2008), mixed forests along the BaltimoreWashington corridor (2003) and the White River National Wildlife Refuge in Arkansas (2006). These LVIS data sets were all collected during the leaf-on season.

We also included a $30 \mathrm{~m}$ resolution Landsat LAI map to examine the spatial distribution of GLAS total LAI. Landsat has the longest Earth observation history at moderate resolution $(30 \mathrm{~m})$, and for decades has provided a consistent and unique measurement of terrestrial ecosystems. The Landsat LAI map was produced using Global Land Survey (GLS) 2005 orthorectified Landsat data (Ganguly et al., 2012, 2016).

\subsection{Analysis}

The comparison between LVIS and GLAS was performed at the GLAS footprint level. LVIS shots falling within a $32.5 \mathrm{~m}$ radius from a GLAS shot center were selected. We filtered GLAS footprints to have a minimum of three coincident LVIS shots to increase the likelihood that the LVIS data covered a sufficient portion of the larger GLAS footprints. Both LAI and the $5 \mathrm{~m}$ interval VFP of LVIS shots were averaged onto each coincident GLAS footprint for comparison. We also made a footprint level comparison between GLAS LAI and the Landsat LAI map. A $3 \times 3$ Landsat window was applied to each GLAS footprint center to extract the averaged Landsat LAI pixels. Pixels with invalid values (e.g., retrieval failure or non-vegetation pixels) were excluded from the comparison. Agreements of different LAI data sets were assessed by coefficient of determination, bias and RMSE (root mean square error):

$$
\begin{aligned}
& \text { bias }=\sum_{i=1}^{n} \frac{\operatorname{GLAS}_{i}-\operatorname{Ref}_{i}}{n}, \\
& \text { RMSE }=\sqrt{\frac{\sum_{i=1}^{n}\left(\mathrm{GLAS}_{i}-\operatorname{Ref}_{i}\right)^{2}}{n} .}
\end{aligned}
$$

In Eqs. (1) and (2), GLAS $i$ is the GLAS LAI (or VFP) value at footprint level and $\operatorname{Ref}_{i}$ is that extracted from LVIS or Landsat.

Next, we aggregated the footprint level GLAS data into terrestrial ecoregions based on a subset of a global map (Olson et al., 2001). Statistical analysis of total LAI and LAI strata (VFP aggregated at every $10 \mathrm{~m}$ height interval) was performed subsequently for each ecoregion. We also analyzed the GLAS LAI and VFP distribution across different environmental gradients throughout CONUS. GLAS footprints were categorized according to different environmental factors, including vegetation type, topographic data and annual measurements of climate variables. The vegetation map was derived from the MODIS Land Cover Type product (MCD12Q1) at $500 \mathrm{~m}$ resolution following the IGBP scheme (Friedl et al., 2010). Elevation data were extracted from the void-filled $90 \mathrm{~m}$ resolution SRTM (Shuttle Radar Topography Mission) DEM (digital elevation model) data (Reuter et al., 2007). Precipitation, temperature and vapor pressure deficit information originated from the $800 \mathrm{~m}$ resolution $30 \mathrm{yr}$ annual normal climate data developed by the PRISM Climate Group (PRISM, 2013).

\section{Results}

This section includes three major parts: the first part focuses on the validation and comparison of GLAS LAI and VFP data with existing products; the second presents the geographical distribution of GLAS LAI and VFP; and the last part shows their relationship with environmental factors.

\subsection{GLAS LAI and VFP comparisons with LVIS and Landsat}

The footprint level comparison between GLAS LAI and LVIS LAI had an overall $r^{2}$ of 0.60 , bias of -0.23 , and RMSE of 0.82 (Fig. 1). Except for a few outliers at the lower range of LAI, most of the comparison points were distributed along the $1: 1$ line, suggesting no systematic difference between the two data sets. No significant bias was found across individual sites either.

The agreement of the $5 \mathrm{~m}$ height interval VFP distributions between the two data sets was lower than that of total LAI $\left(r^{2}=0.36\right.$, bias $=-0.04$, RMSE $\left.=0.26\right)$. Although there was no systematic bias observed when all sites and vertical intervals are considered (Fig. 2), examination by layer showed that GLAS overestimated understory LAI (0 


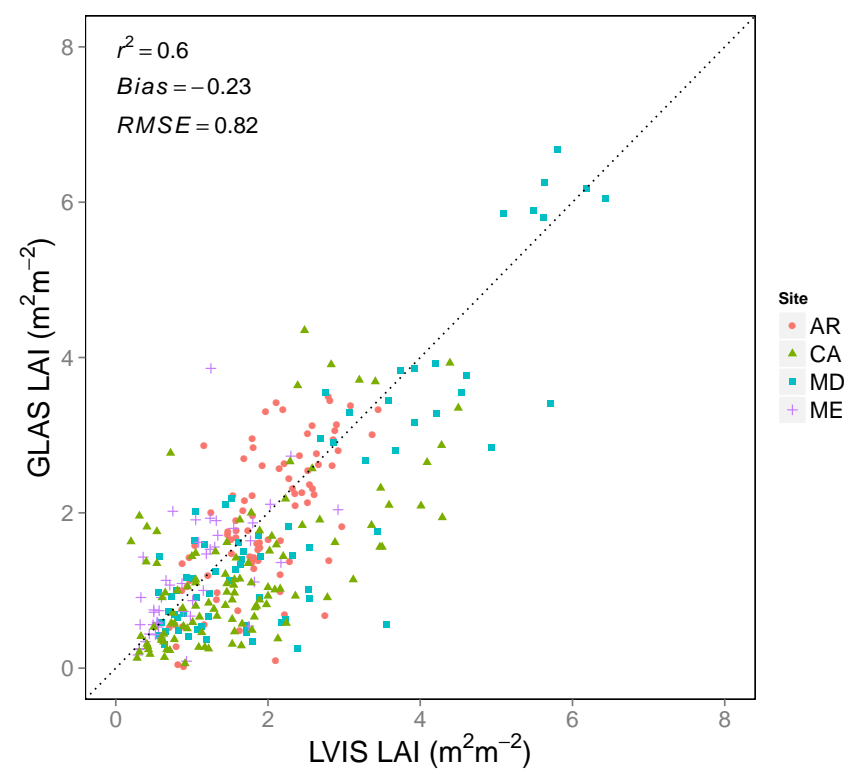

Figure 1. A comparison between two lidar-derived leaf area index (LAI) data sets at different sites across the US $(N=318)$, produced from the Laser Vegetation Imaging Sensor (LVIS) and the Geoscience Laser Altimeter System (GLAS), respectively. Each point represents a comparison at the GLAS footprint, while different colors and shapes indicate different sites (AR: White River National Wildlife Refuge in Arkansas; CA: Sierra National Forest in California; MD: Baltimore-Washington corridor in Maryland; ME: Maine forests to the north of Orono, Maine). The comparison produces $r^{2}$ of 0.60 , bias of -0.23 , and RMSE of 0.82 ). Dashed line is the $1: 1$ line.

to $5 \mathrm{~m})\left(r^{2}=0.04\right.$, bias $=0.09$, RMSE $\left.=0.31\right)$ when compared with LVIS LAI (Fig. 3), but agreement improved as the vertical height interval considered moved higher in the canopy ( 5 to $10 \mathrm{~m}, r^{2}=0.33$, bias $=-0.13$, RMSE $=0.29$; and 10 to $15 \mathrm{~m}, r^{2}=0.53$, bias $=-0.08$, $\operatorname{RMSE}=0.22$ ), reaching a maximum at the top of the canopy ( 15 to $20 \mathrm{~m}$, $r^{2}=0.66$, bias $=-0.05$, RMSE $=0.20$ ) .

The comparison between Landsat LAI and GLAS LAI had a much lower agreement than that of LVIS $\left(r^{2}=0.18\right.$, bias $=0.18$, RMSE = 2.02) (Fig. 4). Even though the two data sets agreed well at lower LAI values, Landsat overestimated LAI at the middle range (from LAI values of 1 to 3 ) and then saturated above a value of about 4 to 5 against GLAS data.

\subsection{Aggregated GLAS LAI and VFP within ecoregions}

We next mapped GLAS LAI across US ecoregions (Fig. 5). Highest LAI values were found along the northern Pacific coast, while lowest values occurred in the basin and range province and the arid rain shadow region east of the Rocky Mountains. Northern California coastal forests (Pacific temperate rainforests) were found to have the highest mean LAI value of 5.24. In the eastern US, the mixed deciduous forests

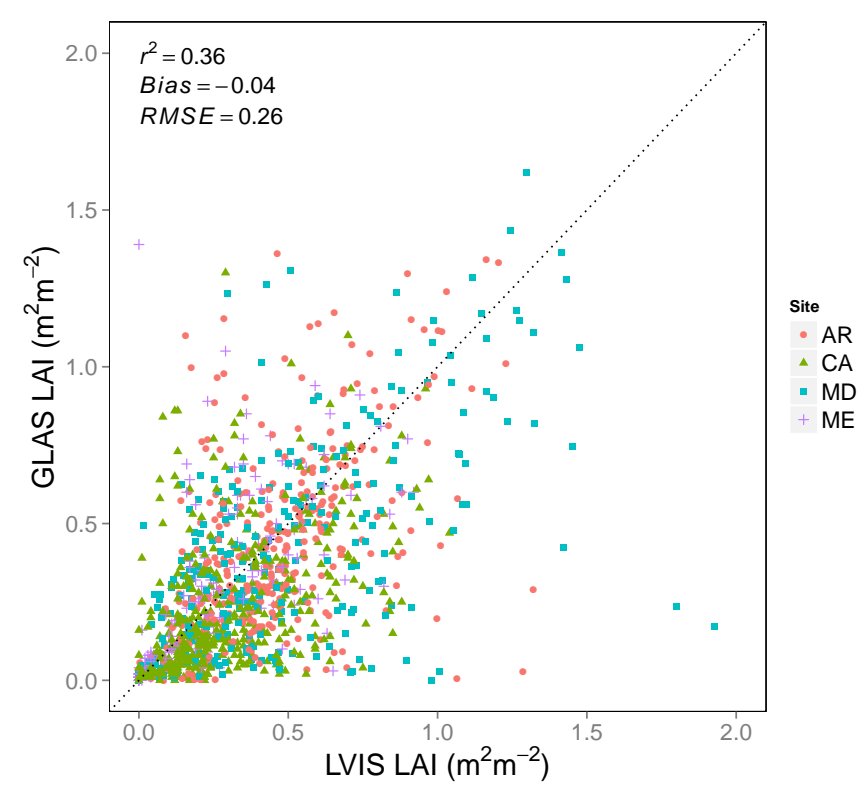

Figure 2. A comparison of vertical foliage profile (VFP) density derived from LVIS and GLAS over different sites in the US (same sites as Fig. 1 but with $N=1272$ ). Each VFP point represents an integrated value of foliage density at each $5 \mathrm{~m}$ height interval.

of the Appalachian-Blue Ridge province had the highest value of 3.95, while other ecogreions around the north-south direction of the Appalachian Mountains had similar LAI values around 3-4 (Table 1). Forest ecogreions with lowest LAI values (excluding desert, shrubland and grassland) were located in Arizona mountain forests (1.15) and Great Basin montane forests (0.90). Differences between these ecoregion-level LAI values were significant based on a Bonferroni adjusted $t$ test, except for those among Willamette Valley forests, Appalachian-Blue Ridge forests, Puget lowland forests and Appalachian mixed mesophytic forests ( $p$ values $>0.05$ ).

LAI strata formed by VFP at each $10 \mathrm{~m}$ height interval were also averaged and mapped across the US (Fig. 6). We chose the $10 \mathrm{~m}$ height interval rather than that of $5 \mathrm{~m}$ because LAI strata aggregated at the $10 \mathrm{~m}$ height interval represented a more accurate and reliable description of vertical canopy structure given the relatively lower measurement accuracy in the understory $(<5 \mathrm{~m})$ we found in comparison to LVIS data. Each strata showed a generally similar geographic pattern to that of total LAI with the decreasing trend from coast to interior lands, but the specific patterns among strata differed. Northwestern forests were observed to have the highest total LAI values as well as LAI strata values. Northern California coastal forests exhibited the largest total LAI value as well as highest foliage density under $20 \mathrm{~m}$ height, while British Columbia mainland coastal forests showed the highest foliage density (1.13) above $20 \mathrm{~m}$ height, with a lower total LAI value (4.74). 

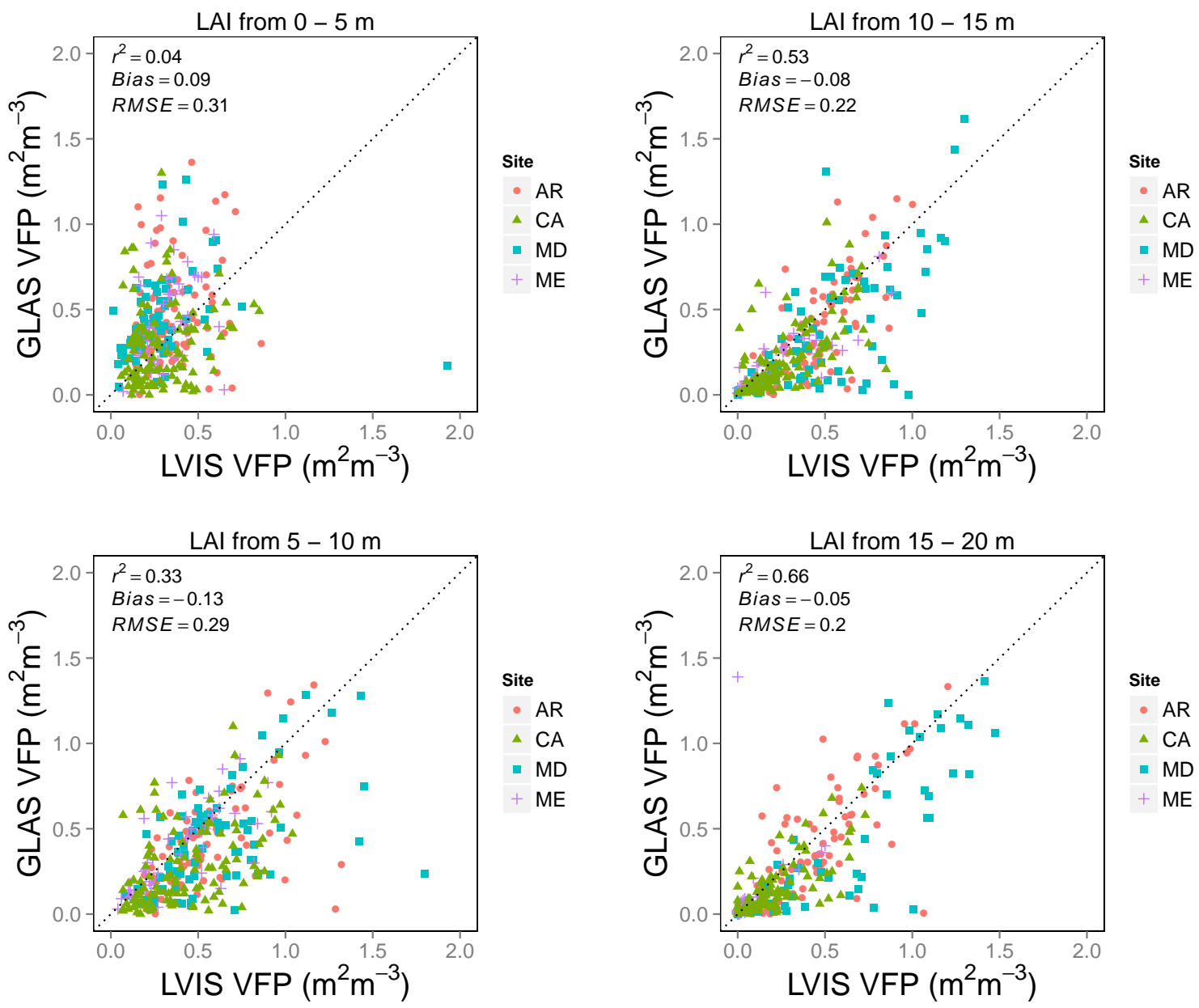

Figure 3. Comparison between LVIS and GLAS VFP density integrated at every $5 \mathrm{~m}$ height interval (from ground to canopy top).
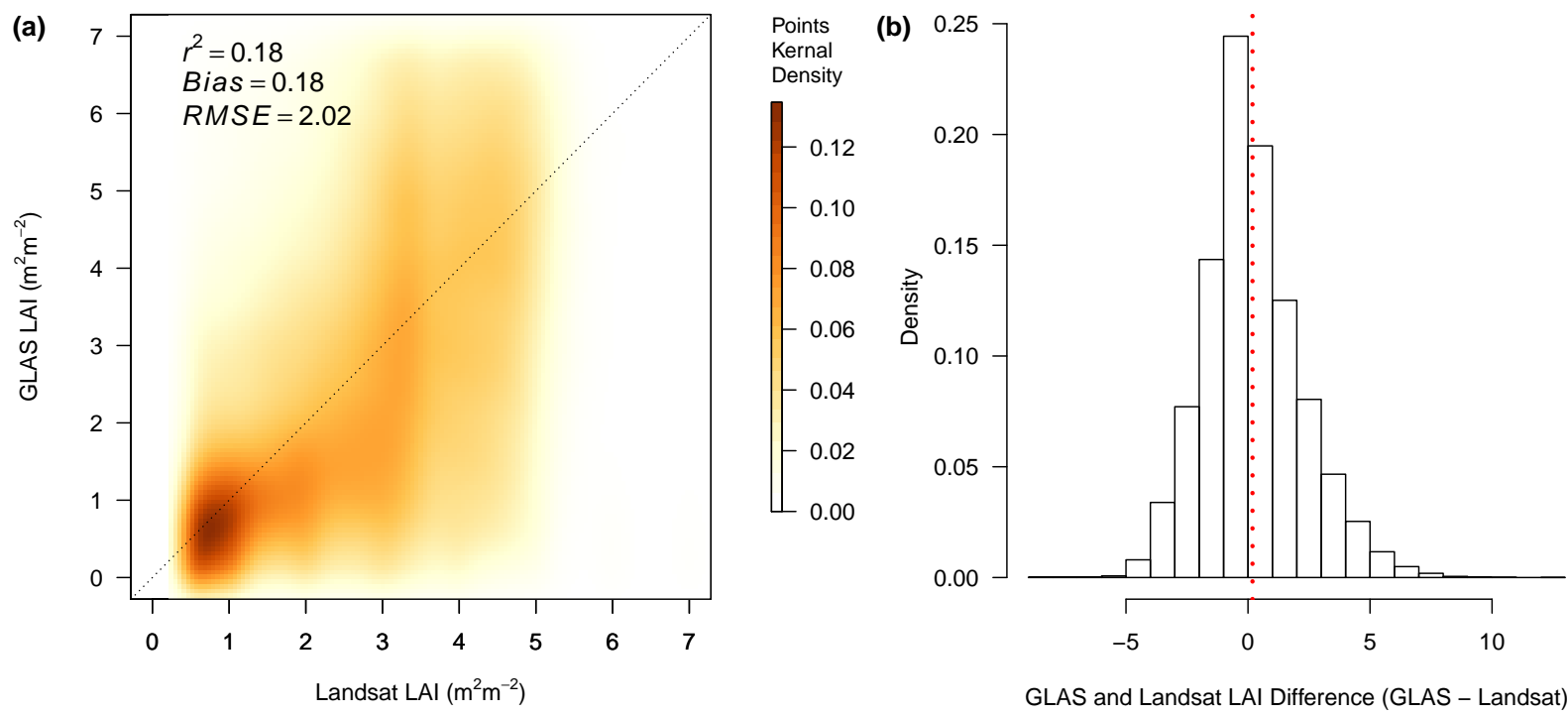

GLAS and Landsat LAI Difference (GLAS - Landsat)

Figure 4. Comparison between Landsat LAI and GLAS LAI over the contiguous US: (a) density scatter plot of Landsat and GLAS LAI $\left(r^{2}=0.18\right.$, bias $=0.18$ and RMSE $\left.=2.02\right)$; (b) difference between Landsat and GLAS LAI. Darker kernel density color refers to a more clustered distribution of LAI pairs. 
Table 1. Ecoregions with highest total LAI values (unit: $\mathrm{m}^{2} \mathrm{~m}^{-2}$ ).

\begin{tabular}{lllll}
\hline Ecoregions & $\begin{array}{l}\text { Total LAI mean } \\
( \pm \text { SD })\end{array}$ & $\begin{array}{l}\text { LAI 0-10 m mean } \\
( \pm \text { SD })\end{array}$ & $\begin{array}{l}\text { LAI 10-20 m mean } \\
( \pm S D)\end{array}$ & $\begin{array}{l}\text { LAI }>20 \mathrm{~m} \text { mean } \\
( \pm \text { SD })\end{array}$ \\
\hline Northern California coastal forests & $5.24 \pm 2.11$ & $2.06 \pm 1.32$ & $1.67 \pm 1.09$ & $1.08 \pm 1.15$ \\
Central Pacific coastal forests & $5.00 \pm 2.14$ & $1.52 \pm 1.61$ & $1.10 \pm 1.16$ & $0.84 \pm 1.25$ \\
British Columbia mainland coastal forests & $4.74 \pm 2.26$ & $1.48 \pm 1.31$ & $1.23 \pm 1.08$ & $1.13 \pm 1.13$ \\
Central and Southern Cascades forests & $4.31 \pm 2.34$ & $1.06 \pm 1.35$ & $0.79 \pm 1.02$ & $0.64 \pm 1.07$ \\
Klamath-Siskiyou forests & $4.31 \pm 2.31$ & $1.26 \pm 1.30$ & $0.99 \pm 1.07$ & $0.73 \pm 0.99$ \\
Willamette Valley forests & $3.99 \pm 2.24$ & $0.73 \pm 1.09$ & $0.60 \pm 0.89$ & $0.75 \pm 1.31$ \\
Appalachian-Blue Ridge forests & $3.95 \pm 2.03$ & $1.04 \pm 1.27$ & $0.82 \pm 0.99$ & $0.47 \pm 0.82$ \\
Puget lowland forests & $3.91 \pm 2.25$ & $0.98 \pm 1.39$ & $0.71 \pm 1.08$ & $0.40 \pm 0.81$ \\
Appalachian mixed mesophytic forests & $3.86 \pm 2.04$ & $1.06 \pm 1.29$ & $0.77 \pm 0.93$ & $0.48 \pm 0.83$ \\
North Central Rockies forests & $3.67 \pm 2.27$ & $1.61 \pm 1.55$ & $0.84 \pm 0.89$ & $0.47 \pm 0.72$
\end{tabular}

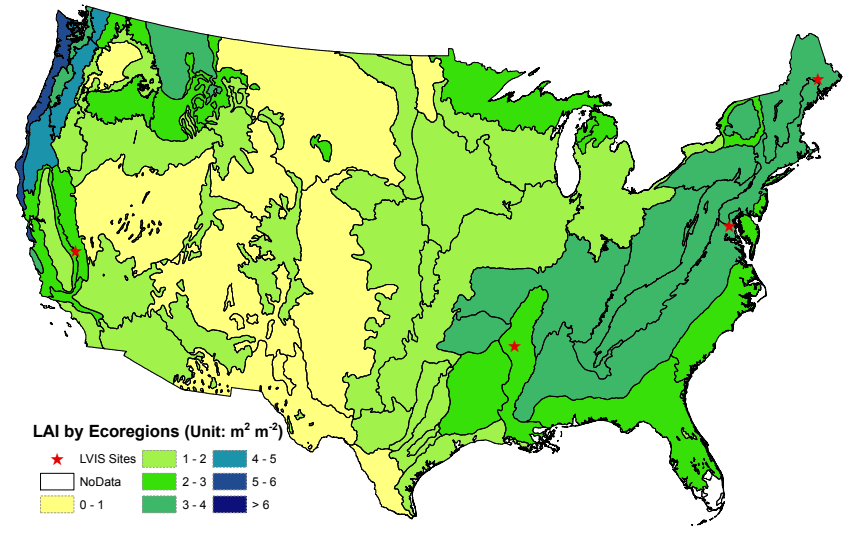

Figure 5. GLAS LAI distributions by ecoregion. All LVIS sites are marked with red stars.

The distributions of GLAS total LAI and profiles were examined across different land cover types (Figs. 7 and 8). Not surprisingly, forests were found to have a consistently greater value than non-forest biomes in both total LAI and its strata. For example, deciduous broadleaf forests had the highest value of total LAI (mean $=4.03$ ) as well as that of middle and upper LAI strata (height $>10 \mathrm{~m}$ ), while open shrubland showed the lowest total LAI values of 0.77 . However, vertical LAI distributions of most forests and non-forests were similar, with peak foliage density distributed around a height of $2-4 \mathrm{~m}$. The only exception was deciduous broadleaf forest, of which most leaves were distributed at middle-story level with a peak height at about $8 \mathrm{~m}$. Its VFP values did not decrease significantly until they reached a height of $15 \mathrm{~m}$.

\subsection{GLAS LAI distributions by environmental factors}

A linear regression analysis between GLAS LAI and the SRTM DEM showed that increasing altitude led to an overall decreasing, but non-monotonic, trend in LAI values $\left(\mathrm{LAI}=3.60-0.686 \times\right.$ Elevation $(\mathrm{km}), r^{2}=0.59$, all $P<0.01$ ) (Fig. 9). GLAS LAI values increased with the (a)

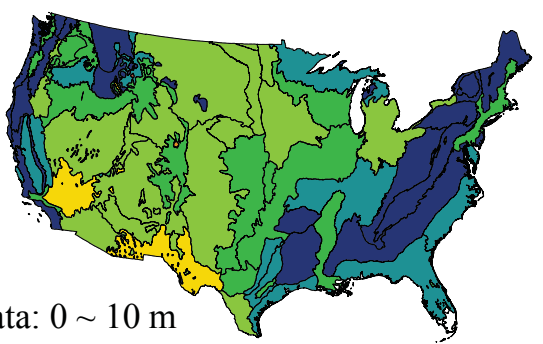

(b)

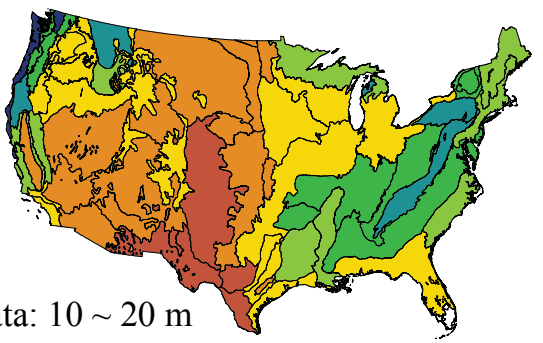

(c)

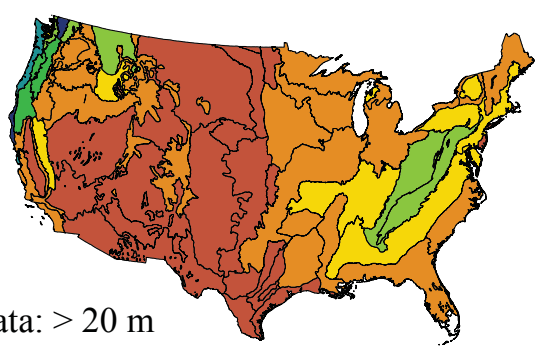

LAI strata: $>20 \mathrm{~m}$

Stratified LAI Values by Ecoregions (Unit: $\mathrm{m}^{2} \mathrm{~m}^{-3}$ )

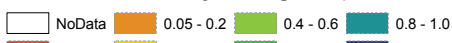

Figure 6. LAI strata distributions by WWF ecoregion. Despite similar total LAI values, the southeastern forests show different LAI values at stratified height intervals.

DEM at the elevation ranges from 0 to $750 \mathrm{~m}$ and 2000 to $3000 \mathrm{~m}$. The variation in the LAI-DEM relationship agreed well with the Forest Ratio (LAI $=0.112+3.18 \times$ Forest Ratio, $\left.r^{2}=0.45, P<0.01\right)$. Here each GLAS footprint was 


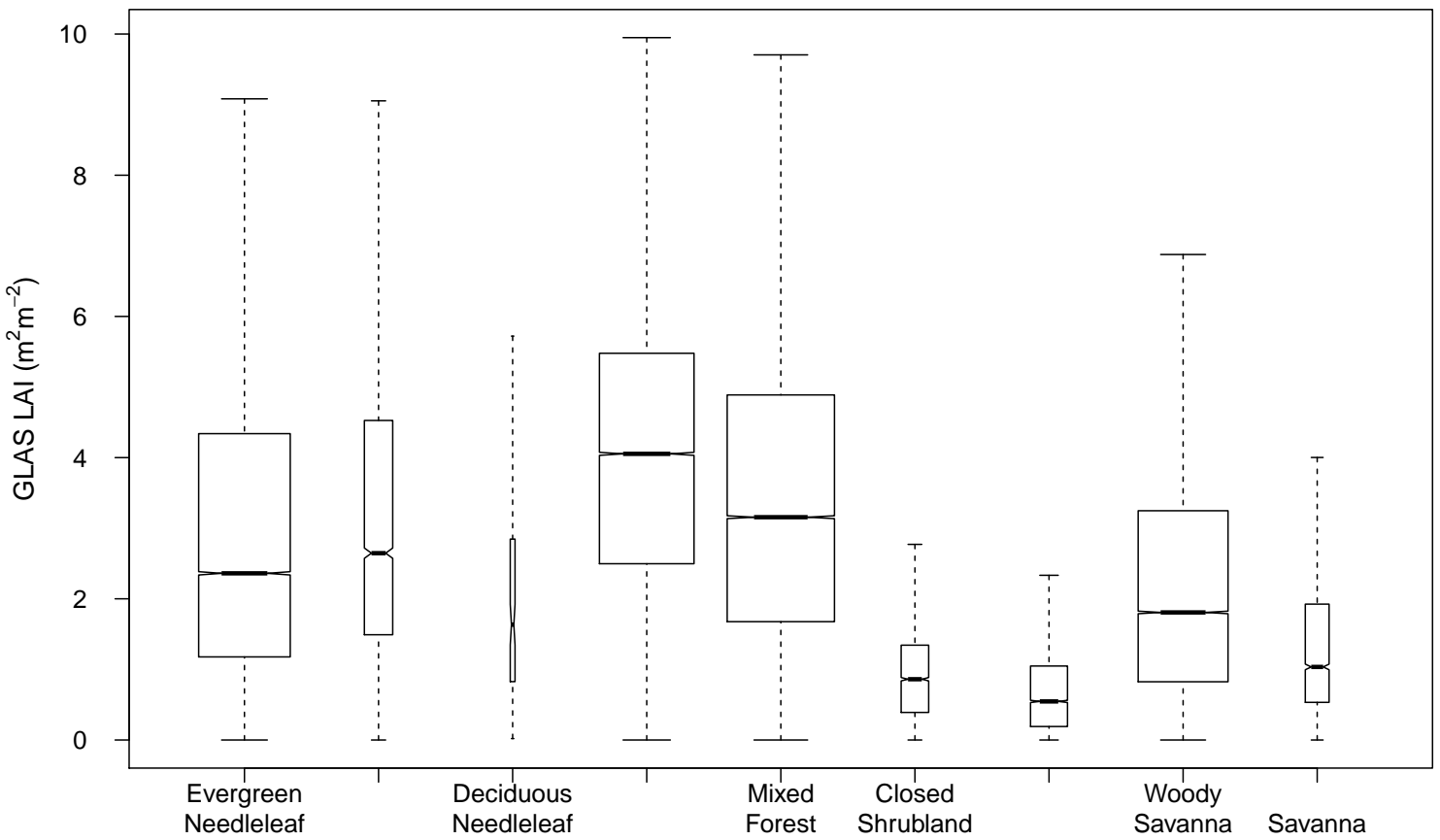

Figure 7. Distribution of total GLAS LAI across different land cover types. The width of the boxes is proportional to the number of observations for each type ( $N$ : Evergreen Needleleaf: 45 207; Evergreen Broadleaf: 438; Deciduous Needleleaf: 123; Deciduous Broadleaf: 48 283; Mixed Forest: 62 053; Closed Shrubland: 4087; Open Shrubland: 7364; Woody Savanna: 43 536; Savanna: 3051). Notches show the approximate $95 \%$ confidence interval of the median.
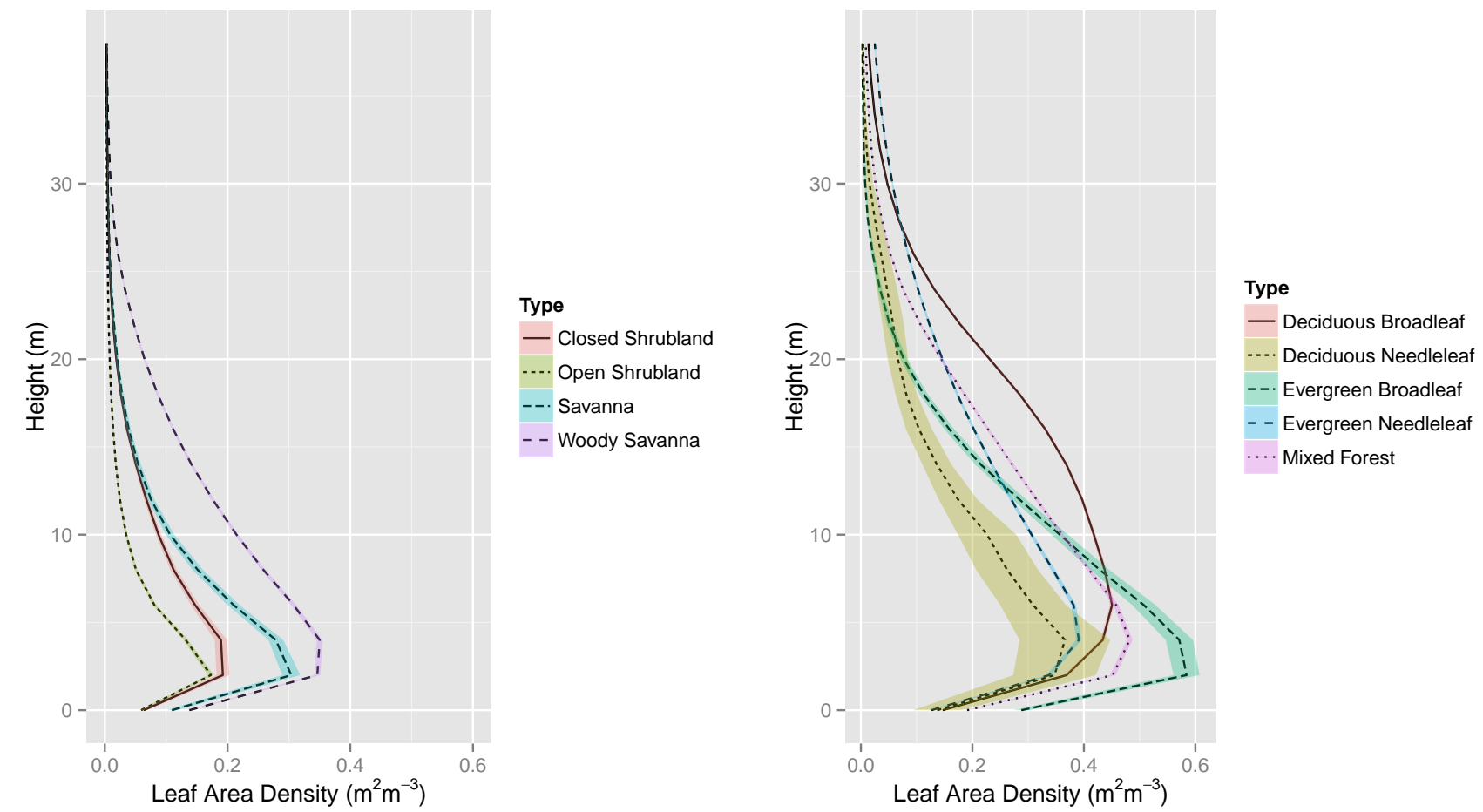

Figure 8. Averaged GLAS VFP for different land cover types across the US: non-forest vegetation types (left) and forest types (right). Mean values are central lines within the color-filled $95 \%$ CI envelope. 
classified as either forest or non-forest with an overlay of the MODIS land cover map, and the forest ratio was defined as the percentage of footprints classified as forests in total GLAS shots within each elevation group. A multiple linear regression analysis showed that about $87 \%$ of total variance could be explained by a simple combination of Elevation groups and Forest Ratio values: $\mathrm{LAI}=2.59 \times$ Forest Ratio $-0.595 \times$ Elevation $(\mathrm{km})+1.58$.

We also analyzed GLAS LAI by $30 \mathrm{yr}$ normal annual climate data using linear regression models (Fig. 10). It was observed that increasing precipitation significantly increased LAI values $(\triangle \mathrm{LAI}=1.84$ per $1000 \mathrm{~mm}$ precipitation increase), but only at low and moderate precipitation levels $(<2400 \mathrm{~mm})$ : $\mathrm{LAI}=1.84 \times$ precipitation $(\mathrm{mm}) \times 10^{-3}+$ $0.774, r^{2}=0.96$, adj- $r^{2}=0.95, P<0.01$. It contributed little when exceeding that threshold $(\mathrm{LAI}=0.22 \times$ precipitation $\left.(\mathrm{mm}) \times 10^{-3}, r^{2}=0.40, \operatorname{adj}-r^{2}=0.30, P=0.09\right)$, as we found no significant LAI increase among groups greater than $2400 \mathrm{~mm}$ using a Bonferroni adjusted $t$ test. GLAS LAI was also negatively but slightly correlated with minimum (maximum) vapor pressure deficit with a Pearson's correlation coefficient of $-0.29(-0.15)$. The correlation coefficients between GLAS LAI and annual mean/minimum/maximum temperature were even lower, with values of $0.13,0.18$ and 0.08 , respectively.

Finally, we applied multiple linear regression analysis to illustrate the combined environmental effects of altitude and precipitation on the distributions of LAI and VFP. The regression analyses were conducted at both GLAS footprint level and aggregated scale on altitude and precipitation groups. At footprint level, altitude and precipitation together explained about $30 \%$ of variance of total LAI (LAI $=2.73-$ $0.69 \times$ Elevation $(\mathrm{km})+0.58 \times$ precipitation $(\mathrm{mm}) \times 10^{-3}$, $r^{2}=0.29$, adj- $\left.r^{2}=0.29, P<0.01\right)$. However, their correlations with footprint level VFP $(0-10,10-20$ and $>20 \mathrm{~m}$ height intervals) were not significant, with $r^{2}$ of $0.07,0.12$ and 0.08 , respectively. At the aggregated scale, there was a better relationship between averaged LAI (VFP) values and environmental factors. The combination of altitude and precipitation can explain more than $60 \%$ variance in both total LAI and VFP, but explains only about $36 \%$ of variance in LAI for canopies of less than $10 \mathrm{~m}$ height.

\section{Discussion}

In this study, we generated GLAS estimates of LAI and VFP across the United States, validated with an airborne lidar sensor, LVIS. Comparisons between LVIS and GLAS LAI and VFP estimates in different forest types across the United States show that GLAS generally provides accurate LAI and VFP estimates at footprint level. Considering the temporal offset and spatial resolution differences between LVIS and GLAS, their overall agreements on LAI and VFP are acceptable $\left(r^{2}=0.60\right.$, bias $=-0.23$, and $\mathrm{RMSE}=0.82$; and $r^{2}=0.36$, bias $=-0.043$, and RMSE $\left.=0.26\right)$. Our comparisons further demonstrate the efficacy of our retrieval methods over continental scales that encompass large gradients in environmental factors and variability in forest types.

Measurement accuracy of GLAS VFP was lower compared to total LAI however $\left(r^{2}=0.36\right.$, bias $=-0.043$, and RMSE $=0.26$ ). Accuracies decreased for the lowest canopy layers, with the $r^{2}$ values falling from a peak of 0.66 at upperstory ( 15 to $20 \mathrm{~m}$ ) to 0.33 at middle-story (5 to $10 \mathrm{~m}$ ), to essentially no relationship in the lowest $5 \mathrm{~m}$ in the understory. There may be multiple factors contributing to this trend. First, a slope effect may reduce measurement accuracy of GLAS (Tang et al., 2014a). Slopes can blur the boundary between vegetation and topography signals in a lidar waveform, making their separation difficult and potentially leading to the error in LAI and VFP estimates. Despite methods to correct for topography (Lee et al., 2011; Tang et al., 2014a; Park et al., 2014), this effect cannot be fully mitigated, especially over steep slopes, and consequently may introduce errors and uncertainties into VFP estimates. Additionally, topographical effects can lead to a vertical misalignment of VFP between LVIS and GLAS. GLAS measures the terrestrial surface at a larger footprint with higher topographical variations, and a direct average of LVIS VFP can possibly result in a mismatch of vertical foliage distribution up to several meters. For example, consider two adjacent LVIS shots with the same VFP distribution but a $1 \mathrm{~m}$ difference in ground elevation (like a signal lag in the waveform). Adding the two waveforms along the geodetic altitude would lead to a $1 \mathrm{~m}$ vertical offset in the averaged waveform (pseudo-GLAS waveform) and produce a different VFP using the direct average method in a normalized coordinate system. But their total LAI values remain the same as long as the total energy from ground and vegetation can be separated correctly. Reducing the vertical resolution of VFPs can partially mitigate the mismatch effect because a lower vertical resolution requires integration over a longer vertical axis that is more tolerant of ground mismatch. Take the above example again: the two VFPs, at $1 \mathrm{~m}$ vertical resolution, do not match each other at all along the entire waveform due to the offset. However, integration at every $5 \mathrm{~m}$ creates a signal overlap of $4 \mathrm{~m}$ in each height bin with a maximum of $20 \%$ measurement error. Thus there is ultimately a tradeoff between vertical resolution and VFP accuracy. It also explains the higher agreement of total LAI (essentially an integration of VFP over the entire canopy) in the comparison between LVIS and GLAS. Lastly, measurement of near-ground understory vegetation by GLAS is difficult. By default, GLAS waveforms are processed by a Gaussian decomposition method to get an approximate fit comprised of a series of Gaussian functions where the last one usually represents the ground (Hofton et al., 2000). The upper tail of the ground Gaussian peak may be mixed with signals from the lower understory, and their separation is problematic, especially over slopes. All of these factors, plus the nature of high complexity and heterogeneity in canopy understory (Aubin 


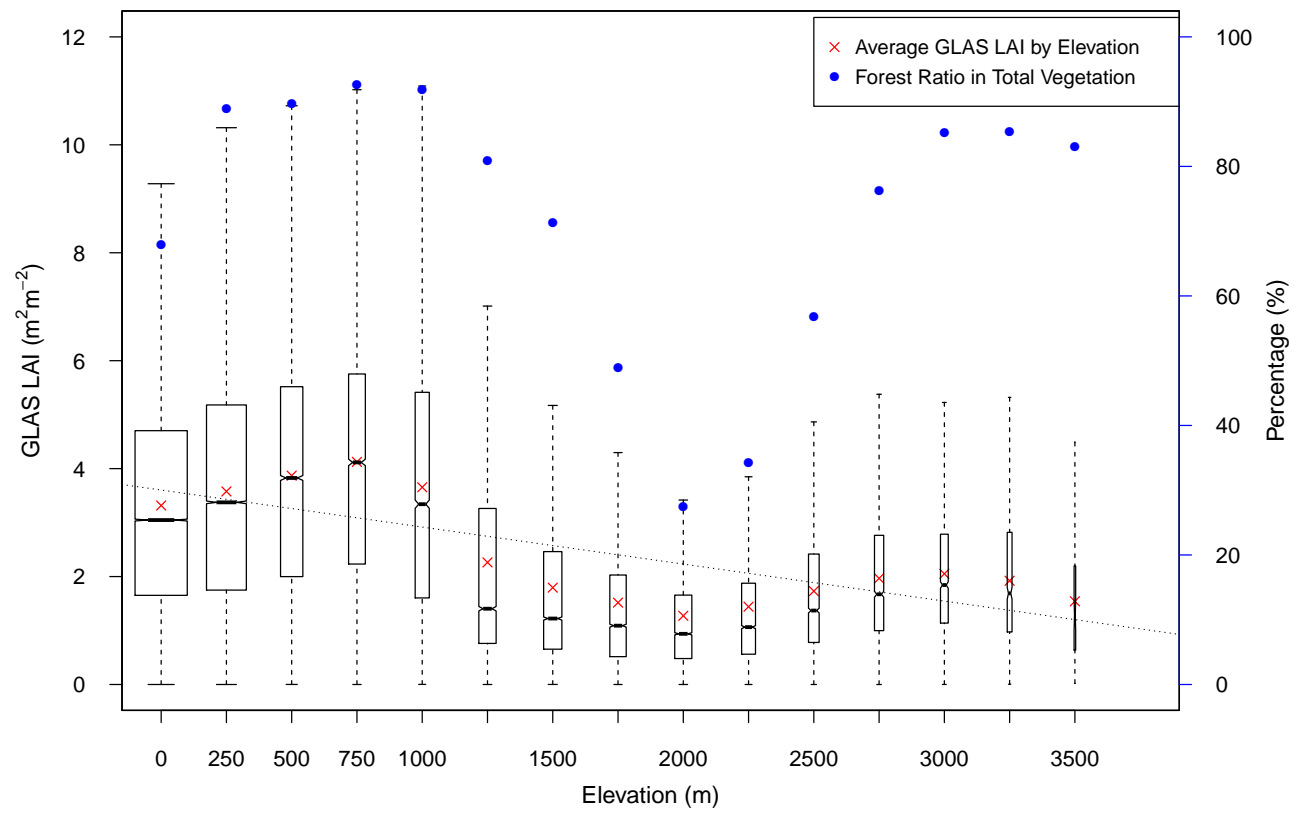

Figure 9. Distribution of GLAS LAI (left axis) and Forest Ratio - GLAS shots over forest divided by total shot numbers (right axis). Overall, there is a decreasing trend of LAI values as elevation increases, but deviations occur from this trend that are associated with elevational variation in the Forest Ratio, which was defined as the percentage of footprints classified as forests in total GLAS shots within each elevation group.

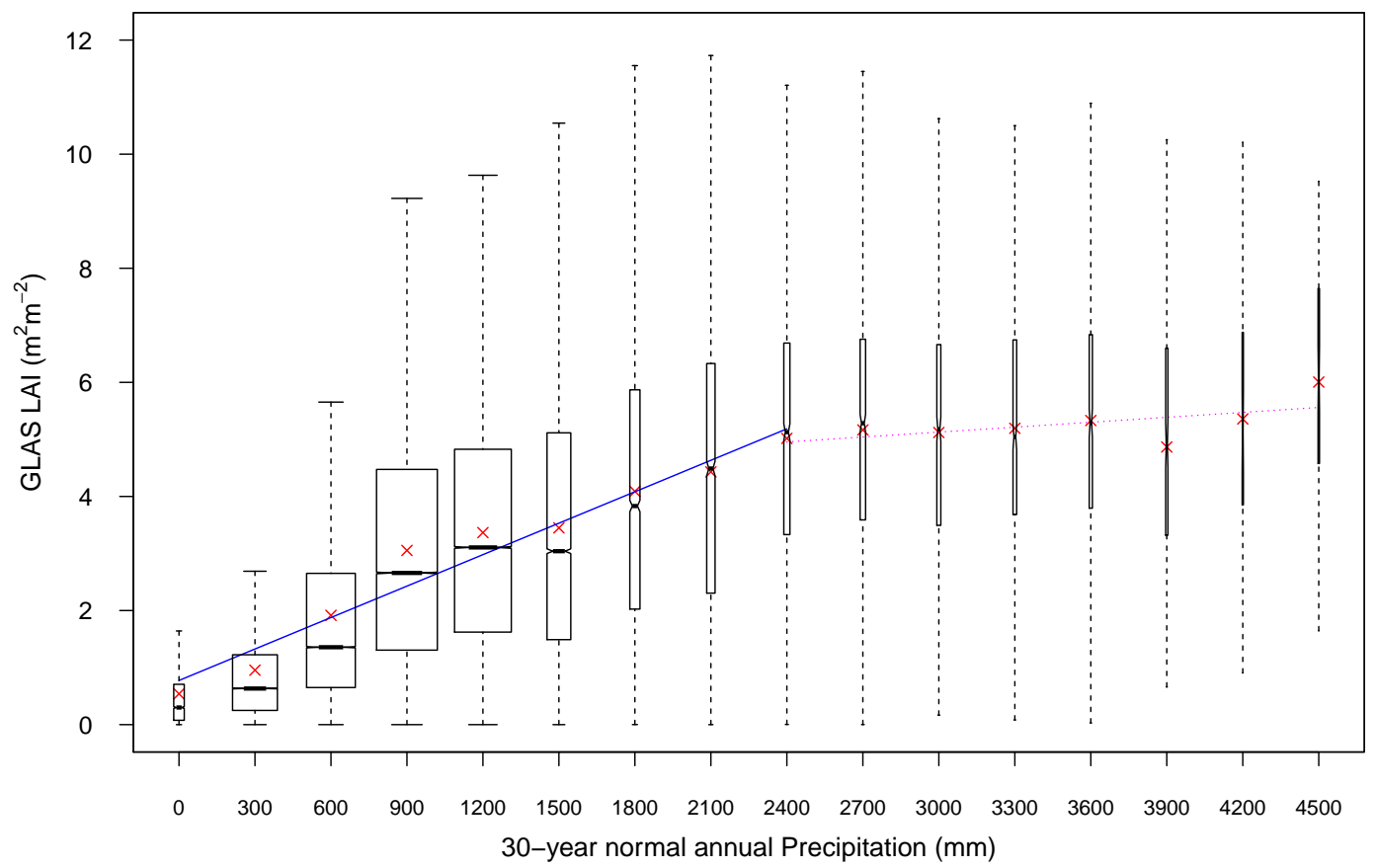

Figure 10. Distribution of GLAS LAI as a function of precipitation. A linear regression analysis of LAI values averaged by precipitation groups shows an increasing trend up to areas of about $2400 \mathrm{~mm}$ (blue line). Beyond this value the rate of change slows considerably (magenta line), but the trend is only weakly significant $(P=0.09)$.

et al., 2000; Valladares and Niinemets, 2008), may help explain the lower agreement on understory VFP between LVIS and GLAS.
Comparison between GLAS and Landsat displayed a much lower agreement than that of LVIS, was somewhat biased, and showed clear signals of saturation beyond LAI val- 
ues of about 5. This result, along with all previous studies (Tang et al., 2012, 2014b), clearly showed the non-saturation advantage of lidar data against passive remote sensing in observing high LAI forests. On the low end of the LAI spectrum, GLAS values were lower as compared with Landsat. There are different factors (some in the LVIS comparison too) that could possibly lead to their difference in LAI estimates such as geolocation errors of GLAS shots, observation-scale difference ( $65 \mathrm{~m}$ vs. $30 \mathrm{~m}$ ) and misclassifications from MODIS land cover types (mainly impacting the correction of the clumping effect). But this underestimation should be largely due to the fact that GLAS may not be able to adequately capture LAI values of short grassland with limited vertical structure or areas of sparse canopy cover, whereas Landsat is able to measure such areas based on their total spectral response (tree and grass).

Analysis of GLAS LAI and VFP across ecoregions displayed a reasonable and expected geographical distribution. The great advantage of lidar-based estimates is that they can produce LAI vertical strata maps, providing a view of canopy variability across ecosystem types over large areas. Specifically, we can identify the foliage concentrations at various vertical bins and at spatial resolutions of interest (Figs. 6 and 8 and Table 1; another example provided in the Supplement). This approach may reduce errors that arise from assumptions of uniformly distributed foliage within canopies, and could potentially be a contribution towards continental-scale ecological and biological studies of forest structure and dynamics.

LAI and VFP also varied across different landscapes represented by various land cover types. As expected, we found that both total LAI and maximum value of foliage density significantly increase along the vegetation gradient described by the transition from shrubland to savanna to woody savanna to forests (Figs. 7 and 8). In particular, we found deciduous broadleaf forest showing a different pattern, with its foliage more evenly distributed in understory and mid-story when compared with all other forests. Our results suggest the existence of canopy layering, and highlight the feasibility of quantifying these layers across landscapes (Whitehurst et al., 2013). Regardless of whether the data are conceptualized as layers or as continuously varying profiles, they nonetheless provide the actual vertical structure, and thus should help refine current empirical assumptions about vegetation structure of different land cover types in current LAI inversion algorithms (e.g., MODIS) and in ecosystem models (Hurtt et al., 2010; Antonarakis et al., 2014).

Elevation and precipitation were found to be significantly correlated with LAI at both footprint level and across aggregated groupings by elevation and the Forest Ratio. LAI decreased with elevation, and this trend was consistent with previous studies (Luo et al., 2004; Moser et al., 2007; Pfeifer et al., 2012). Variations of the trend can be largely explained (about $45 \%$ of total variance) by the Forest Ratio (defined in Sect. 3.3). A combination of the two factors (elevation groups and the Forest Ratio) explained almost $90 \%$ variance of average LAI spatial distribution. We also found a significant but nonlinear relationship between GLAS LAI and annual precipitation (Fig. 10). This nonlinear relationship agrees with previous studies in the tropics (Pfeifer et al., 2014; Spracklen et al., 2012). However, we found no significant variation of GLAS LAI with either temperature or vapor pressure deficit variables. A combined effect of elevation and precipitation explains about $30 \%$ of LAI variation at GLAS footprint level, suggesting the natural complexity and high spatial variability of LAI distribution.

As a direct quantification of three-dimensional foliage distribution, GLAS LAI profiles are thus far the best representations of terrestrial ecosystem structure over broad geographical areas and suggest that ecological applications of these profiles are worth exploring. First, these data could refine large-scale modeling of plant respiration and photosynthesis and consequently improve ecosystem modeling (Houghton, 2007). Previous studies have reported a potential $50 \%$ underestimate of GPP values when vertical foliage stratification is not considered (Kotchenova et al., 2004; Sprintsin et al., 2012). A consistent, global data set of VFP should thus improve initialization of ecological models (Hurtt et al., 2004) and refine estimation of GPP, in conjunction with passive remote sensing data (Turner et al., 2006). Secondly, these profiles may be important descriptors of habitat as related to biodiversity and habitat quality. Many studies have confirmed the general relationship between species richness, habitat heterogeneity and forest structural complexity across different landscapes (Swatantran et al., 2012; Goetz et al., 2010; Schut et al., 2014; Ferger et al., 2014). The inclusion of LAI profiles provides spatially explicit vegetation structure data and may potentially improve current observations of species distribution at continental scale, e.g., for avian species (Sauer et al., 2008; Culbert et al., 2013), and lead to entirely new biodiversity metrics (e.g., see Huang et al., 2014). For example, the concept of an "edge" has been traditionally defined as the boundary between forest and nonforest areas. LAI profiles provide a means of defining new edges based on differences in LAI as a function of height, so the edge is now the boundary between a rapid change in foliage density at a particular height.

\section{Conclusions}

Accurate representation of canopy vertical structure and its dynamics has long been recognized as a priority because it represents a key interface between terrestrial surface and atmosphere and impacts the water and carbon cycles, and their transfer of energy and mass. Foliar profiles are also increasingly recognized as important determinants for habitat quality, species distribution, diversity and abundance. As ecosystems come under increasing pressure from climate and land use change, global data sets of canopy structure are needed 
to help better understand the consequences of these changes for ecosystem form, function and services.

In this paper we have demonstrated the potential for global mapping of key canopy structures, LAI and VFP, from space. While imperfect, given their large footprint and sparse sampling, the waveforms from ICESat are currently the only such global data set of structure. Our ability to produce this data set is the end result of a series of research experiments that linked various types of observations, from destructive profiles, to ground-based optical methods, to airborne lidar, to passive optical retrievals. This background gives us confidence that meaningful and useful data on LAI and VFP can be derived from future spaceborne lidar. There are still hurdles to overcome related to topography, understory accuracy, model assumptions and parameterizations, such as groundcanopy reflectance ratios and foliage clumping, among others, to achieving higher accuracy. We anticipate that these will be resolved in time and lead to an even more capable model suitable for the next generation of waveform lidar observations from space, such as NASA's Global Ecosystem Dynamics Investigation (GEDI) (Dubayah et al., 2014) and, potentially, ICESat-2 (Abdalati et al., 2009).

\section{The Supplement related to this article is available online at doi:10.5194/bg-13-239-2016-supplement.}

Acknowledgements. This work was funded by NASA under grant NNX12AK07G (Dubayah) and an Earth and Space Science graduate fellowship, NNX12AN43H (Dubayah and Tang). We thank Helen G. Cornejo and Wenli Huang for the raw LVIS waveform process, and George Hurtt and Shunlin Liang for their advice on product development. We also thank the NSIDC (National Snow \& Ice Data Center) User Services for their help on data acquisition and NASA Earth Exchange (NEX) for computing resources.

Edited by: M. Bahn

\section{References}

Abdalati, W., Zwally, H. J., Bindschadler, R., Csatho, B., Farrell, S. L., Fricker, H. A., Harding, D., Kwok, R., Lefsky, M., Markus, T., Marshak, A., Neumann, T., Palm, S., Schutz, B., Smith, B., Spinhirne, J., and Webb, C.: The ICESat-2 laser altimetry mission, Proc. IEEE, 98, 735-751, 2009.

Aber, J. D.: Foliage-height profiles and succession in northern hardwood forests, Ecology, 60, 18-23, 1979.

Abshire, J. B., Sun, X., Riris, H., Sirota, J. M., McGarry, J. F., Palm, S., Yi, D., and Liiva, P.: Geoscience Laser Altimeter System (GLAS) on the icesat mission: On-orbit measurement performance, Geophys. Res. Lett., 32, L21S02, doi:10.1029/2005GL024028, 2005.
Abuelgasim, A. A., Fernandes, R. A., and Leblanc, S. G.: Evaluation of national and global lai products derived from optical remote sensing instruments over canada, IEEE Trans. Geosci. Remote Sens., 44, 1872-1884, 2006.

Antonarakis, A. S., Munger, J. W., and Moorcroft, P. R.: Imaging spectroscopy- and lidar-derived estimates of canopy composition and structure to improve predictions of forest carbon fluxes and ecosystem dynamics, Geophys. Res. Lett., 41, 2535-2542, 2014.

Asner, G. P., Knapp, D. E., Boardman, J., Green, R. O., KennedyBowdoin, T., Eastwood, M., Martin, R. E., Anderson, C., and Field, C. B.: Carnegie airborne observatory-2: Increasing science data dimensionality via high-fidelity multi-sensor fusion, Remote Sens. Environ., 124, 454-465, 2012.

Asner, G. P., Mascaro, J., Anderson, C., Knapp, D. E., Martin, R. E., Kennedy-Bowdoin, T., van Breugel, M., Davies, S., Hall, J. S., Muller-Landau, H. C., Potvin, C., Sousa, W., Wright, J., and Bermingham, E.: High-fidelity national carbon mapping for resource management and redd+, Carbon Bal. Manage., 8, 7, doi:10.1186/1750-0680-8-7, 2013.

Aubin, I., Beaudet, M., and Messier, C.: Light extinction coefficients specific to the understory vegetation of the southern boreal forest, quebec, Can. J. Forest Res., 30, 168-177, 2000.

Baccini, A., Goetz, S. J., Walker, W. S., Laporte, N. T., Sun, M., Sulla-Menashe, D., Hackler, J., Beck, P. S. A., Dubayah, R., Friedl, M. A., Samanta, S., and Houghton, R. A.: Estimated carbon dioxide emissions from tropical deforestation improved by carbon-density maps, Nat. Clim. Change, 2, 182-185, 2012.

Baret, F., Hagolle, O., Geiger, B., Bicheron, P., Miras, B., Huc, M., Berthelot, B., Nino, F., Weiss, M., Samain, O., Roujean, J. L., and Leroy, M.: Lai, fapar and fcover cyclopes global products derived from vegetation - part 1: Principles of the algorithm, Remote Sens. Environ., 110, 275-286, 2007.

Baret, F., Weiss, M., Lacaze, R., Camacho, F., Makhmara, H., Pacholcyzk, P., and Smets, B.: Geov1: Lai and fapar essential climate variables and fcover global time series capitalizing over existing products. Part1: Principles of development and production, Remote Sens. Environ., 137, 299-309, 2013.

Blair, J. B., Rabine, D. L., and Hofton, M. A.: The laser vegetation imaging sensor (LVIS): A medium-altitude, digitizationonly, airborne laser altimeter for mapping vegetation and topography, ISPRS J. Photogramm. Remote Sens., 54, 115-122, 1999.

Brenner, A. C., Zwally, H. J., Bentley, C. R., Csatho, B. M., Harding, D. J., Hofton, M. A., Minster, J.-B., Roberts, L., Saba, J. L., and Thomas, R. H.: The algorithm theoretical basis document for the derivation of range and range distributions from laser pulse waveform analysis for surface elevations, roughness, slope, and vegetation heights, Goddard Space Flight Center, Greenbelt, MD, United States, Technical Report NASA/TM2012-208641/Vol 7, GSFC.TM.7299.2012, 2012.

Chopping, M., Nolin, A., Moisen, G. G., Martonchik, J. V., and Bull, M.: Forest canopy height from the multiangle imaging spectroradiometer (MISR) assessed with high resolution discrete return lidar, Remote Sens. Environ., 113, 2172-2185, 2009.

Clark, D. B. and Kellner, J. R.: Tropical forest biomass estimation and the fallacy of misplaced concreteness, J. Vegetat. Sci., 23, 1191-1196, 2012.

Cramer, W., Bondeau, A., Woodward, F. I., Prentice, I. C., Betts, R. A., Brovkin, V., Cox, P. M., Fisher, V., Foley, J. A., Friend, A. D., Kucharik, C., Lomas, M. R., Ramankutty, N., Sitch, S., 
Smith, B., White, A., and Young-Molling, C.: Global response of terrestrial ecosystem structure and function to $\mathrm{CO}_{2}$ and climate change: Results from six dynamic global vegetation models, Glob. Change Biol., 7, 357-373, 2001.

Culbert, P. D., Radeloff, V. C., Flather, C. H., Kellndorfer, J. M., Rittenhouse, C. D., and Pidgeon, A. M.: The influence of vertical and horizontal habitat structure on nationwide patterns of avian biodiversity, Auk, 130, 656-665, 2013.

Deng, F., Chen, J. M., Plummer, S., Chen, M. Z., and Pisek, J.: Algorithm for global leaf area index retrieval using satellite imagery, IEEE Trans. Geosci. Remote Sens., 44, 2219-2229, 2006.

Drake, J. B., Dubayah, R. O., Clark, D. B., Knox, R. G., Blair, J. B., Hofton, M. A., Chazdon, R. L., Weishampel, J. F., and Prince, S. D.: Estimation of tropical forest structural characteristics using large-footprint lidar, Remote Sens. Environ., 79, 305-319, 2002.

Dubayah, R., Bergen, K., Hall, F., Hurtt, G., Houghton, R., Kellndorfer, J., Lefsky, M., Moorcroft, P., Nelson, R., and Saatchi, S.: Global vegetation structure from nasa's desdyni mission: An overview, AGU Fall Meeting Abstracts, 01, San Francisco, 15 December, B31H-01, 2008.

Dubayah, R., Goetz, S., Blair, J. B., Fatoyinbo, T., Hansen, M., Healey, S., Hofton, M., Hurtt, G., Kellner, J. R., Luthcke, S. B., and Swatantran, A.: The global ecosystem dynamics investigation, American Geophysical Union, Fall Meeting 2014, San Francisco, 15 December, U14A-07, 2014.

Ferger, S. W., Schleuning, M., Hemp, A., Howell, K. M., and Böhning-Gaese, K.: Food resources and vegetation structure mediate climatic effects on species richness of birds, Glob. Ecol. Biogeogr., 23, 541-549, 2014.

Friedl, M. A., Sulla-Menashe, D., Tan, B., Schneider, A., Ramankutty, N., Sibley, A., and Huang, X. M.: Modis collection 5 global land cover: Algorithm refinements and characterization of new datasets, Remote Sens. Environ., 114, 168-182, 2010.

Ganguly, S., Nemani, R. R., Zhang, G., Hashimoto, H., Milesi, C., Michaelis, A., Wang, W. L., Votava, P., Samanta, A., Melton, F., Dungan, J. L., Vermote, E., Gao, F., Knyazikhin, Y., and Myneni, R. B.: Generating global leaf area index from landsat: Algorithm formulation and demonstration, Remote Sens. Environ., 122, 185-202, 2012.

Ganguly, S. et al.: Generating leaf area index from landsat over the Unites States, in preparation, 2016.

Garcia, M., Popescu, S., Riano, D., Zhao, K., Neuenschwander, A., Agca, M., and Chuvieco, E.: Characterization of canopy fuels using ICESat/GLAS data, Remote Sens. Environ., 123, 81-89, 2012.

Goetz, S., Steinberg, D., Dubayah, R., and Blair, B.: Laser remote sensing of canopy habitat heterogeneity as a predictor of bird species richness in an eastern temperate forest, USA, Remote Sens. Environ., 108, 254-263, 2007.

Goetz, S. J., Steinberg, D., Betts, M. G., Holmes, R. T., Doran, P. J., Dubayah, R., and Hofton, M.: Lidar remote sensing variables predict breeding habitat of a neotropical migrant bird, Ecology, 91, 1569-1576, 2010.

Gower, S. T. and Norman, J. M.: Rapid estimation of leaf area index in conifer and broad-leaf plantations, Ecology, 72, 1896-1900, 1991.

Harding, D. J. and Carabajal, C. C.: ICESat waveform measurements of within-footprint topographic relief and vege- tation vertical structure, Geophys. Res. Lett., 32, L21s10, doi:10.1029/2005g1023471, 2005.

Healey, S. P., Patterson, P. L., Saatchi, S., Lefsky, M. A., Lister, A. J., and Freeman, E. A.: A sample design for globally consistent biomass estimation using lidar data from the Geoscience Laser Altimeter System (GLAS), Carb. Bal. Manage., 7, 10, doi:10.1186/1750-0680-7-10, 2012.

Heimann, M. and Reichstein, M.: Terrestrial ecosystem carbon dynamics and climate feedbacks, Nature, 451, 289-292, 2008.

Hofton, M. A., Minster, J. B., and Blair, J. B.: Decomposition of laser altimeter waveforms, IEEE Trans. Geosci. Remote Sens., 38, 1989-1996, 2000.

Houghton, R. A.: Balancing the global carbon budget, Ann. Rev. Earth Planet. Sci., 35, 313-347, 2007.

Huang, Q. Y., Swatantran, A., Dubayah, R., and Goetz, S. J.: The influence of vegetation height heterogeneity on forest and woodland bird species richness across the united states, Plos One, 9, e103236, doi:10.1371/journal.pone.0103236, 2014.

Hurtt, G. C., Dubayah, R., Drake, J., Moorcroft, P. R., Pacala, S. W., Blair, J. B., and Fearon, M. G.: Beyond potential vegetation: Combining lidar data and a height-structured model for carbon studies, Ecol. Appl., 14, 873-883, 2004.

Hurtt, G. C., Fisk, J., Thomas, R. Q., Dubayah, R., Moorcroft, P. R., and Shugart, H. H.: Linking models and data on vegetation structure, J. Geophys. Res.-Biogeosci., 115, G00e10, doi:10.1029/2009jg000937, 2010.

Kotchenova, S. Y., Song, X. D., Shabanova, N. V., Potter, C. S., Knyazikhin, Y., and Myneni, R. B.: Lidar remote sensing for modeling gross primary production of deciduous forests, Remote Sens. Environ., 92, 158-172, 2004.

Lee, S., Ni-Meister, W., Yang, W. Z., and Chen, Q.: Physically based vertical vegetation structure retrieval from icesat data: Validation using LVIS in white mountain national forest, new hampshire, USA, Remote Sens. Environ., 115, 2776-2785, 2011.

Lefsky, M. A.: A global forest canopy height map from the moderate resolution imaging spectroradiometer and the geoscience laser altimeter system, Geophys. Res. Lett., 37, L15401, doi:10.1029/2010GL043622, 2010.

Lefsky, M. A., Cohen, W. B., Parker, G. G., and Harding, D. J.: Lidar remote sensing for ecosystem studies, BioScience, 52, 1919, 2002.

Loreau, M., Naeem, S., Inchausti, P., Bengtsson, J., Grime, J. P., Hector, A., Hooper, D. U., Huston, M. A., Raffaelli, D., Schmid, B., Tilman, D., and Wardle, D. A.: Ecology - biodiversity and ecosystem functioning: Current knowledge and future challenges, Science, 294, 804-808, 2001.

Los, S. O., Rosette, J. A. B., Kljun, N., North, P. R. J., Chasmer, L., SuÃjrez, J. C., Hopkinson, C., Hill, R. A., van Gorsel, E., Mahoney, C., and Berni, J. A. J.: Vegetation height and cover fraction between $60^{\circ} \mathrm{S}$ and $60^{\circ} \mathrm{N}$ from ICESat GLAS data, Geosci. Model Dev., 5, 413-432, doi:10.5194/gmd-5-413-2012, 2012.

Luo, S. Z., Wang, C., Li, G. C., and Xi, X. H.: Retrieving leaf area index using icesat/glas full-waveform data, Remote Sens. Lett., 4, 745-753, 2013.

Luo, T. X., Pan, Y. D., Ouyang, H., Shi, P. L., Luo, J., Yu, Z. L., and Lu, Q.: Leaf area index and net primary productivity along subtropical to alpine gradients in the tibetan plateau, Glob. Ecol. Biogeogr., 13, 345-358, 2004. 
Morsdorf, F., Kotz, B., Meier, E., Itten, K., and Allgower, B.: Estimation of lai and fractional cover from small footprint airborne laser scanning data based on gap fraction, Remote Sens. Environ., 104, 50-61, 2006.

Moser, G., Hertel, D., and Leuschner, C.: Altitudinal change in lai and stand leaf biomass in tropical montane forests: A transect shady in ecuador and a pan-tropical meta-analysis, Ecosystems, 10, 924-935, 2007.

Mu, Q., Heinsch, F. A., Zhao, M., and Running, S. W.: Development of a global evapotranspiration algorithm based on modis and global meteorology data, Remote Sens. Environ., 111, 519536, 2007.

Myneni, R. B., Hoffman, S., Knyazikhin, Y., Privette, J. L., Glassy, J., Tian, Y., Wang, Y., Song, X., Zhang, Y., Smith, G. R., Lotsch, A., Friedl, M., Morisette, J. T., Votava, P., Nemani, R. R., and Running, S. W.: Global products of vegetation leaf area and fraction absorbed par from year one of modis data, Remote Sens. Environ., 83, 214-231, 2002.

Ni-Meister, W., Jupp, D. L. B., and Dubayah, R.: Modeling lidar waveforms in heterogeneous and discrete canopies, IEEE Trans. Geosci. Remote Sens., 39, 1943-1958, 2001.

Nilson, T.: A theoretical analysis of the frequency of gaps in plant stands, Agr. Meteorol., 8, 25-38, 1971.

Olson, D. M., Dinerstein, E., Wikramanayake, E. D., Burgess, N. D., Powell, G. V. N., Underwood, E. C., D'amico, J. A., Itoua, I., Strand, H. E., Morrison, J. C., Loucks, C. J., Allnutt, T. F., Ricketts, T. H., Kura, Y., Lamoreux, J. F., Wettengel, W. W., Hedao, P., and Kassem, K. R.: Terrestrial ecoregions of the world: A new map of life on earth: A new global map of terrestrial ecoregions provides an innovative tool for conserving biodiversity, BioScience, 51, 933-938, 2001.

Park, T., Kennedy, R. E., Choi, S. H., Wu, J. W., Lefsky, M. A., Bi, J., Mantooth, J. A., Myneni, R. B., and Knyazikhin, Y.: Application of physically-based slope correction for maximum forest canopy height estimation using waveform lidar across different footprint sizes and locations: Tests on lvis and glas, Remote Sens., 6, 6566-6586, 2014.

Pereira, H. M., Ferrier, S., Walters, M., Geller, G. N., Jongman, R. H. G., Scholes, R. J., Bruford, M. W., Brummitt, N., Butchart, S. H. M., Cardoso, A. C., Coops, N. C., Dulloo, E., Faith, D. P., Freyhof, J., Gregory, R. D., Heip, C., Hoft, R., Hurtt, G., Jetz, W., Karp, D. S., McGeoch, M. A., Obura, D., Onoda, Y., Pettorelli, N., Reyers, B., Sayre, R., Scharlemann, J. P. W., Stuart, S. N., Turak, E., Walpole, M., and Wegmann, M.: Essential biodiversity variables, Science, 339, 277-278,

Pfeifer, M., Gonsamo, A., Disney, M., Pellikka, P., and Marchant, R.: Leaf area index for biomes of the eastern arc mountains: Landsat and spot observations along precipitation and altitude gradients, Remote Sens. Environ., 118, 103-115, 2012.

Pfeifer, M., Lefebvre, V., Gonsamo, A., Pellikka, P., Marchant, R., Denu, D., and Platts, P.: Validating and linking the gimms leaf area index (LAI3g) with environmental controls in tropical africa, Remote Sens., 6, 1973-1990, 2014.

PRISM: 30 yr normal precipitation: annual, in: 1981-2010, August 2013 Edn., PRISM Climate Group, Oregon State University, Corvallis, OR, 2013.

Randerson, J. T., Hoffman, F. M., Thornton, P. E., Mahowald, N. M., Lindsay, K., Lee, Y. H., Nevison, C. D., Doney, S. C., Bonan, G., Stockli, R., Covey, C., Running, S. W., and Fung, I.
Y.: Systematic assessment of terrestrial biogeochemistry in coupled climate-carbon models, Glob. Change Biol., 15, 2462-2484, 2009.

Reuter, H. I., Nelson, A., and Jarvis, A.: An evaluation of voidfilling interpolation methods for srtm data, Int. J. Geogr. Informat. Sci., 21, 983-1008, 2007.

Saatchi, S. S., Harris, N. L., Brown, S., Lefsky, M., Mitchard, E. T. A., Salas, W., Zutta, B. R., Buermann, W., Lewis, S. L., Hagen, S., Petrova, S., White, L., Silman, M., and Morel, A.: Benchmark map of forest carbon stocks in tropical regions across three continents, Proc. Natl. Acad. Sci. USA, 108, 9899-9904, 2011.

Sauer, J. R., Hines, J. E., Fallon, J., Pardieck, K., Ziolkowski Jr., D., and Link, W.: The north american breeding bird survey, results and analysis 1966-2007, Version, 5, Laurel, MD, USGS Patuxent Wildlife Research Center, 2008

Schimel, D. S., House, J. I., Hibbard, K. A., Bousquet, P., Ciais, P., Peylin, P., Braswell, B. H., Apps, M. J., Baker, D., Bondeau, A., Canadell, J., Churkina, G., Cramer, W., Denning, A. S., Field, C. B., Friedlingstein, P., Goodale, C., Heimann, M., Houghton, R. A., Melillo, J. M., Moore, B., Murdiyarso, D., Noble, I., Pacala, S. W., Prentice, I. C., Raupach, M. R., Rayner, P. J., Scholes, R. J., Steffen, W. L., and Wirth, C.: Recent patterns and mechanisms of carbon exchange by terrestrial ecosystems, Nature, 414, 169172, 2001.

Schut, A. G. T., Wardell-Johnson, G. W., Yates, C. J., Keppel, G., Baran, I., Franklin, S. E., Hopper, S. D., Van Niel, K. P., Mucina, L., and Byrne, M.: Rapid characterisation of vegetation structure to predict refugia and climate change impacts across a global biodiversity hotspot, Plos One, 9, e82778, doi:10.1371/journal.pone.0082778, 2014.

Shabanov, N. V., Huang, D., Yang, W. Z., Tan, B., Knyazikhin, Y., Myneni, R. B., Ahl, D. E., Gower, S. T., Huete, A. R., Aragao, L. E. O. C., and Shimabukuro, Y. E.: Analysis and optimization of the modis leaf area index algorithm retrievals over broadleaf forests, IEEE Trans. Geosci. Remote Sens., 43, 18551865, 2005.

Simard, M., Pinto, N., Fisher, J. B., and Baccini, A.: Mapping forest canopy height globally with spaceborne lidar, J. Geophys. Res.Biogeosci., 116, G04021, doi:10.1029/2011jg001708, 2011.

Spracklen, D. V., Arnold, S. R., and Taylor, C. M.: Observations of increased tropical rainfall preceded by air passage over forests, Nature, 489, 282-U127, doi:10.1038/Nature11390, 2012.

Sprintsin, M., Chen, J. M., Desai, A., and Gough, C. M.: Evaluation of leaf-to-canopy upscaling methodologies against carbon flux data in north america, J. Geophys. Res.-Biogeosci., 117, G01023, doi:10.1029/2010jg001407, 2012.

Stahl, G., Holm, S., Gregoire, T. G., Gobakken, T., Naesset, E., and Nelson, R.: Model-based inference for biomass estimation in a lidar sample survey in hedmark county, norway, Can. J. Forest Res., 41, 96-107, 2011.

Strahler, A. H., Jupp, D. L. B., Woodcock, C. E., Schaaf, C. B., Yao, T., Zhao, F., Yang, X., Lovell, J., Culvenor, D., Newnham, G., NiMiester, W., and Boykin-Morris, W.: Retrieval of forest structural parameters using a ground-based lidar instrument $\left(\right.$ echidna $\left.{ }^{\circledR}\right)$, Can. J. Remote Sens., 34, S426-S440, 2008.

Swatantran, A., Dubayah, R., Goetz, S., Hofton, M., Betts, M. G., Sun, M., Simard, M., and Holmes, R.: Mapping migratory bird prevalence using remote sensing data fusion, Plos One, 7, e28922, doi:10.1371/journal.pone.0028922, 2012. 
Tang, H., Dubayah, R., Swatantran, A., Hofton, M., Sheldon, S., Clark, D. B., and Blair, B.: Retrieval of vertical lai profiles over tropical rain forests using waveform lidar at la selva, costa rica, Remote Sens. Environ., 124, 242-250, 2012.

Tang, H., Brolly, M., Zhao, F., Strahler, A. H., Schaaf, C. L., Ganguly, S., Zhang, G., and Dubayah, R.: Deriving and validating leaf area index (lai) at multiple spatial scales through lidar remote sensing: A case study in sierra national forest, ca, Remote Sens. Environ., 143, 131-141, 2014a.

Tang, H., Dubayah, R., Brolly, M., Ganguly, S., and Zhang, G.: Large-scale retrieval of leaf area index and vertical foliage profile from the spaceborne waveform lidar (glas/icesat), Remote Sens. Environ., 154, 8-18, 2014b.

Turner, D. P., Ritts, W. D., Cohen, W. B., Gower, S. T., Running, S. W., Zhao, M. S., Costa, M. H., Kirschbaum, A. A., Ham, J. M., Saleska, S. R., and Ahl, D. E.: Evaluation of modis npp and gpp products across multiple biomes, Remote Sens. Environ., 102, 282-292, 2006.

Turner, W., Spector, S., Gardiner, N., Fladeland, M., Sterling, E., and Steininger, M.: Remote sensing for biodiversity science and conservation, Trends Ecol. Evolut., 18, 306-314, 2003.

Valladares, F. and Niinemets, U.: Shade tolerance, a key plant feature of complex nature and consequences, Ann. Rev. Ecol. Evolut. System., 39, 237-257, 2008.
Whitehurst, A. S., Swatantran, A., Blair, J. B., Hofton, M. A., and Dubayah, R.: Characterization of canopy layering in forested ecosystems using full waveform lidar, Remote Sens., 5, 20142036, 2013.

Yang, W. Z., Tan, B., Huang, D., Rautiainen, M., Shabanov, N. V., Wang, Y., Privette, J. L., Huemmrich, K. F., Fensholt, R., Sandholt, I., Weiss, M., Ahl, D. E., Gower, S. T., Nemani, R. R., Knyazikhin, Y., and Myneni, R. B.: Modis leaf area index products: From validation to algorithm improvement, IEEE Trans. Geosci. Remote Sens., 44, 1885-1898, 2006.

Zhao, F., Yang, X. Y., Strahler, A. H., Schaaf, C. L., Yao, T., Wang, Z. S., Roman, M. O., Woodcock, C. E., Ni-Meister, W., Jupp, D. L. B., Lovell, J. L., Culvenor, D. S., Newnham, G. J., Tang, H., and Dubayah, R. O.: A comparison of foliage profiles in the sierra national forest obtained with a full-waveform undercanopy evi lidar system with the foliage profiles obtained with an airborne full-waveform lvis lidar system, Remote Sens. Environ., 136, 330-341, 2013.

Zhao, M. S., Heinsch, F. A., Nemani, R. R., and Running, S. W.: Improvements of the modis terrestrial gross and net primary production global data set, Remote Sens. Environ., 95, 164-176, 2005. 